\title{
Prediction of Europium Retention in Perovskite: Potential Candidates for an Engineering Barrier in the Disposal of Radioactive Waste
}

\author{
Huemantzin B. Ortiz-Oliveros $\mathbb{D}^{1},{ }^{1}$ Rosa Ma. Flores Espinosa $\mathbb{D}^{2},{ }^{2}$ Pedro Ávila-Pérez $\mathbb{D}^{\mathbb{D}},{ }^{3}$ \\ Daniel Cruz-Gonzalez $\mathbb{D}^{4},{ }^{4}$ and Noureddine Ouerfelli $\mathbb{i}^{5}$ \\ ${ }^{1}$ Department of Radioactive Waste, National Institute of Nuclear Research, Ocoyoacac, Mexico City, C.P. 52750, Mexico \\ ${ }^{2}$ Department of Environmental Studies, National Institute of Nuclear Research, Ocoyoacac, Mexico City, C.P. 52750, Mexico \\ ${ }^{3}$ Department of Postgraduate, Technological Institute of Toluca, Metepec, C.P. 50120, Mexico \\ ${ }^{4}$ Faculty of Chemical Engineering, Benemerita Autonomous University of Puebla, Puebla, C.P. 72570, Mexico \\ ${ }^{5}$ Institut Supérieur de Technologies Médicales de Tunis, Laboratoire de Biophysique et Technologies Médicales, \\ Université de Tunis El Manar, Tunis, Tunisia \\ Correspondence should be addressed to Huemantzin B. Ortiz-Oliveros; hbortizo@uaemex.mx
}

Received 27 August 2021; Revised 22 September 2021; Accepted 24 September 2021; Published 30 September 2021

Academic Editor: Doina Humelnicu

Copyright (C) 2021 Huemantzin B. Ortiz-Oliveros et al. This is an open access article distributed under the Creative Commons Attribution License, which permits unrestricted use, distribution, and reproduction in any medium, provided the original work is properly cited.

\begin{abstract}
Perovskites, such as tausonite, are crystalline metal oxides with excellent optical and photocatalytic properties and have also been used successfully in the retention of metals, simulating the isotopes of uranium and plutonium. In this work, different pseudoorder and thermodynamic models were studied to achieve the prediction of the sorption of $\mathrm{Eu}^{3+}$ (chemical analogous for actinides) in tausonite. The effects of gamma irradiation and temperature on the structural characteristics of the material were determined, as an additional step in the evaluation of material as an engineering barrier in the disposal of radioactive waste. The results obtained show that the tausonite is resistant to the gamma irradiation and thermal energy. Likewise, it was possible to determine that europium sorption occurs through an exothermic and spontaneous reaction, as well as through the formation of surface complexes, where $\mathrm{Eu}^{3+}$ ions bind to sites on the tausonite by dipole-dipole interaction. Furthermore, it was shown that the sorption mechanism is influenced by diffusive phenomena, which participate in the formation of surface complexes. Additionally, a new sorption model with respect to $\mathrm{pH}$ was proposed, which allowed determining the physical parameter $\pi$. The evidence obtained suggests that $\pi$ is a physical parameter that relates $\mathrm{pH}$ to an optimal value and could explain the equilibrium between the surface complexes that tausonite forms with europium. Likewise, the evidence suggests that $50 \mathrm{~kg}$ of tausonite would have the capacity to retain at least $26.59 \mathrm{~g}$ of alpha-emitting radionuclides, equivalent to a waste package ( $900 \mathrm{~kg}$ ) with a maximum activity of $4000 \mathrm{~Bq} / \mathrm{g}$.
\end{abstract}

\section{Introduction}

Perovskites are crystalline metal oxides with the general formula $\mathrm{ABO}_{3}$, in which $\mathrm{A}$ can be rare earth (mainly lanthanides) or an alkali or alkaline earth metal and $\mathrm{B}$ is a transition metal $[1,2]$. These oxides are excellent light absorbers and their properties include tunable band gaps, low exciton binding energy, high carrier mobility, long diffusion length, and so on [3], and, also, they have a narrow band gap (semiconductor), for which they could be considered as good candidates for thermoelectric generators [4, 5]. Among the different structures of perovskites, those of the $\mathrm{ATiO}_{3}$ type $(\mathrm{A}=\mathrm{Ca}, \mathrm{Ba}, \mathrm{Sr}$, etc. $)$ are the most interesting due to their optical and electronic properties [6,7]. Perovskites have high tolerance to metal substitution in their crystalline structure, excellent thermal stability, and resistance to sintering of substituted metals [8]. These characteristics have allowed them to be used to create different types of materials by 
partial substituting of metals, obtaining modified perovskites that have been used in various photocatalytic applications [9-11]. On the other hand, perovskites, such as tausonite, have been used successfully in the retention of $\mathrm{U}^{6+}$ and $\mathrm{Eu}^{3+}$, simulating the different isotopes of uranium and actinides $\left(\mathrm{Ac}^{3+}\right)$, which are produced in the burning and reprocessing of nuclear fuels $[12,13]$. These studies have shown that perovskites are insoluble in water and have high chemical stability under acidic and alkaline $\mathrm{pH}$ conditions and that retention of $\mathrm{U}$ and $\mathrm{Eu}$ is carried out by the formation of inner-sphere surface complexes at $\mathrm{pH}$ values low and high, respectively [14, 15]. These results reveal the potential of perovskites as materials that could be used as engineering barriers in the disposal of radioactive waste.

The IAEA defines the term "disposal" as the emplacement of radioactive waste into a facility or location with no intention of recovering it, when the objective of the radioactive waste disposal is to protect the environment and people from the potential radiological consequences due to the release and dispersal of radionuclides [16]. Therefore, disposal involves (a) isolating waste from the biosphere and people, reducing the risk of human intrusion, and (b) containing the wastes, inhibiting, reducing, and delaying the migration of radionuclides into the biosphere $[16,17]$. The physical and chemical properties of engineering barriers provide containment of radionuclides. This containment consists of impermeability to water; limited corrosion, dissolution, leaching rate, and solubility; retention of radionuclides; and delayed migration of radionuclides [16].

Typically, the evaluation of materials used as engineering barriers consists of determining their physical and chemical properties, including retention and transport of radionuclides, as well as determining the resistance to degradation of these materials with sources of thermal energy or gamma radiation $[16,17]$.

There are different mathematical models to assess the retention of radionuclides; these are usually classified into two large groups: (a) microscopic or thermodynamic and (b) macroscopic or empirical. The first group explains the physicochemical and thermodynamic phenomena of the medium ( $\mathrm{pH}$, temperature, pressure, redox potential, electrostatic potential, etc.) that influence the retention of sorbate. On the other hand, empirical models simplify these phenomena and focus on establishing the retention kinetics and the affinity of the solid for sorbate.

In the study of the retention capacities of materials used in engineering barriers, it is recommended to use a combination of macroscopic and microscopic models, since they allow estimating important constants and parameters, such as kinetics and sorption capacity, concentration of surface sites, dependence of the surface sites with respect to $\mathrm{pH}$, the formation constants of the surface site, the identification of the surface complexes formed, and the respective complex formation constants, among others. These elements are important in the study of the behavior of engineering barriers for the containment of radionuclides and are part of the "safety case" approach, during the institutional control stage of radioactive waste disposal [18].
Considering that, in previous studies the concentration of surface sites, the dependence of surface sites with respect to $\mathrm{pH}$, the surface site formation constants, identification of surface complexes, and the complex formation constants were established in tausonite $[14,15]$. In this work, the study of different macroscopic pseudo-order models $(0.5 \leq n \leq 2)$ based on the reduced Van't Hoff equation is proposed for the prediction of the sorption of $\mathrm{Eu}^{3+}$ (actinides, $\mathrm{Ac}^{3+}$, and simulating) on tausonite. At the same time, the effects of gamma irradiation $(500,1000,5000$, and $12000 \mathrm{kGy})$ and temperature $(25-1273.15 \mathrm{~K})$ on the structural characteristics of the material were determined, as an additional step in the evaluation of tausonite as an engineering barrier in the disposal of radioactive waste. Likewise, the use of optimal modelling of europium retention in the material seeks a new phenomenological point of view that contributes to the discussion and specific interpretation of the new parameters. Therefore, this work also seeks to contribute to the environmental and global challenge that radioactive waste management represents, evaluating materials that can be used successfully in the isolation and containment of radioactive waste.

\section{Materials and Methods}

2.1. Materials. All reagents used in the experimental tests were analytical grade. Strontium titanate (tausonite) of 99.5\% purity (Sigma-Aldrich) was used as an engineering barrier (sorbent). Likewise, potassium nitrate (SigmaAldrich, $\geq 99 \%$ ) was used as the background salt. Europium nitrate (Aldrich, 99.9\%) was used for the experimental sorption tests on perovskite. All solutions were prepared with deionized water under nitrogen flow.

\subsection{Gamma Irradiation and Effect of Temperature on} Tausonite. Gamma irradiation of perovskite was performed to determine the structural changes due to gamma radiation. Exposure to gamma radiation was performed in a JS-6500 industrial irradiator containing a ${ }^{60} \mathrm{Co}$ source of $28971.56 \mathrm{TBq}$ (1 July 2018). The solid was placed in aluminum containers (in duplicate) and subjected to a dose of $500 \mathrm{kGy}, 1000 \mathrm{kGy}, 5000 \mathrm{kGy}$, and $12000 \mathrm{kGy}$, applying a dose rate calculated between $14.09 \mathrm{kGy} / \mathrm{h}$ and $14.37 \mathrm{kGy} / \mathrm{h}(8$ September 2018).

The effects of gamma radiation on the structure of tausonite were evaluated by X-ray diffraction (XRD) and scanning electron microscopy (SEM). Tausonite XRD patterns were obtained on a Siemens D-5000 diffractometer using $\mathrm{Cu} \mathrm{K} \alpha 1$ radiation. At the same time, a Philips XL-30 scanning electron microscope coupled with energy dispersive X-ray spectroscopy (EDS) was used to study the morphology of the samples. In addition, the effects of temperature on tausonite were evaluated by thermogravimetric analysis (TGA).

Thermogravimetric analyses were performed with a heating rate of $283.15 \mathrm{~K} / \mathrm{min}$ up to $1273.15 \mathrm{~K} / \mathrm{min}$, flowing $\mathrm{N}_{2}$ (Q600 Calorimeter, T.A. Instruments-Waters LLC) to determine the loss of mass at high temperatures. In addition, 
the tausonite samples were calcined at $1023.15 \mathrm{~K}\left(750^{\circ} \mathrm{C}\right)$ and $1173.15 \mathrm{~K}\left(900^{\circ} \mathrm{C}\right)$ and analyzed by IR spectroscopy. The IR spectrum of the solid was recorded in the range of $4000-400 \mathrm{~cm}^{-1}$ with a Perkin Elmer 1600 FT-IR spectrometer. Samples of the material were mixed with $\mathrm{KBr}$ (infrared grade) in a ratio of $1: 200$.

Finally, the specific area, pore volume, and mean pore diameter of the material were determined by interpreting the adsorption-desorption isotherms for $\mathrm{N}_{2}$ by the standard multipoint BET method (Brunauer-Emmett-Teller) in a Belsorp Max equipment (Japan INC).

2.3. Sorption Experiments. Europium sorption experiments on tausonite were carried out using a solution of $1 \times 10^{-4} \mathrm{M}$ europium nitrate in $0.5 \mathrm{M}$ potassium nitrate at room temperature under a nitrogen atmosphere. Sorption kinetics and modelling of europium retention as a function of $\mathrm{pH}$ were performed in batch. Finally, the quantification of europium was performed by luminescence in a Jobin Yvon Horiba Fluorolog with a xenon lamp $(450 \mathrm{~W}) .500 \mu \mathrm{L}$ samples of the supernatant were excited at $397 \mathrm{~nm}$ and europium emission spectra were recorded from $570 \mathrm{~nm}$ to $650 \mathrm{~nm}$ and the highest peaks were quantified at $590 \mathrm{~nm}$ and $610 \mathrm{~nm}[13,19]$.

2.4. Sorption Kinetics Modelling. The europium sorption isotherms as a function of time were developed by estimating the concentration of europium nitrate retained in tausonite at different contact times $(1,2,3,4,5,7,16,18,20,22,24$, and $48 \mathrm{~h})$. Sorption kinetics were modelled using pseudo-order expressions $(0.5 \leq n \leq 2)$, based on the reduced Van't Hoff equation (see equation (1)) and compared with empirical pseudo-first-order model (Lagergren and Elovich equation), pseudo-second-order, and intraparticle diffusion. Van't Hoff relationship was given by

$$
\frac{d C_{(t)}}{d t}=k_{n} C_{(t)}
$$

where $C_{(t)}$ is the sorbate concentration as a function of time, $n$ represents the order of the reaction, and $k$ is the sorption kinetic constant. The sorbate concentration retained in the material is usually expressed as the sorption capacity $\left(q_{t}\right)$, as presented in

$$
q_{t}=\frac{\left(C_{i}-C_{(t)}\right)}{m} V,
$$

where $m$ is the mass of the sorbent, $V$ is the volume of the sorbate solution, and $C_{i}$ is the initial concentration of the sorbate. The general equations and their linear representation used were expressed in terms of $q_{t}$ and $q_{e}$ (sorption capacity at equilibrium) [20-27].

2.5. Modelling Concentration Dependence on $p H$. Sorption isotherms were obtained by measuring the europium concentration as a function of $\mathrm{pH}$, adjusting the solutions to the desired $\mathrm{pH}$ value (1 to 13), which were left for $24 \mathrm{~h}$ at $45 \mathrm{rpm}$. The $\mathrm{pH}$ was measured using a $\mathrm{HACH}$ SensION + potentiometer combined with an $\mathrm{Ag} / \mathrm{AgCl}$ electrode. Likewise, the modelling of the concentration dependence as a function of $\mathrm{pH}$ considered the adjustment of three parameters: the europium concentration, $\mathrm{pH}$, and a factor called $\pi$.

2.6. Thermodynamic Study. The distribution coefficients $\left(K_{d}\right)$ for tausonite and europium $\left(5 \times 10^{-4} \mathrm{M}\right)$ in a $0.5 \mathrm{M}$ $\mathrm{KNO}_{3}$ solution were measured at 283, 298, 308, 318, and $333 \mathrm{~K}$ using the previously described procedure [15]. All experimental data are the average of duplicate batches with good reproducibility (standard deviations were typically less than $5 \%$ of the mean values).

Enthalpy change $\left(\Delta H^{\circ}\right)$, entropy change $\left(\Delta S^{\circ}\right)$, and Gibbs free energy changes $\left(\Delta G^{\circ}\right)$ at different temperatures were estimated with equation (3) and europium sorption data [28]:

$$
\Delta G_{T}^{\circ}=-R T \ln K d_{T}^{\circ}
$$

where $K d_{T}^{\circ}$ is an equilibrium constant at absolute temperature $T$ and the perfect gas constant $R=8.3144721 \mathrm{~J} / \mathrm{kmol}$.

The two main thermodynamic parameters, such as $\Delta H^{\circ}$ and $\Delta S^{\circ}$, can be determined from the basic thermodynamic expression (equation (4)), where the Gibbs free energy is expressed as follows:

$$
\Delta G_{T}^{\circ}=\Delta H^{\circ}-T \Delta S^{\circ} .
$$

To determine the two thermodynamic parameters $\Delta H^{\circ}$ and $\Delta S^{\circ}$, the linearized equation of (4) was used. The linearized expression relates the Gibbs free energy at temperature $\left(\Delta G^{\circ} / T\right)$ with the reciprocal of the absolute temperature $(1 / T)$. Practically, all experiments fit the thermodynamic behavior of the experimental data by linear regression (equation (5)) to determine the global thermal character of the studied process (i.e., endothermic or inverse) $[28,29]$ :

$$
\frac{\Delta G_{T}^{\circ}}{T}=\Delta H^{\circ}\left(\frac{1}{T}\right)-\Delta S^{\circ} .
$$

\section{Results and Discussion}

3.1. Gamma Irradiation and Effect of Temperature on Tausonite. The results obtained from the gamma irradiation of tausonite showed the physical darkening of all the samples because of the gamma dose received. On the other hand, the diffraction patterns of the irradiated samples were compared with the standard number card 35-0734. Figure 1 shows the main diffraction peaks of the samples at $2 \theta=23.0^{\circ}, 32.4^{\circ}$, $40.4^{\circ}, 57.8^{\circ}, 67.8^{\circ}, 77.2^{\circ}$, and $79.9^{\circ}$ belonged to $100,110,111$, $200,211,220$, and 310 , which correspond to tausonite. The diffraction patterns show that in all cases, the material presents an intensity of high diffraction peaks, which indicates a high crystallinity. Furthermore, no phase changes shifts or significant changes in diffraction patterns are observed. However, a decrease in the intensity of the diffraction peaks was observed. The changes observed in the intensity lines can be attributed to two possible reasons. First, due to a mutual torsion of tetrahedra under the effect of gamma 


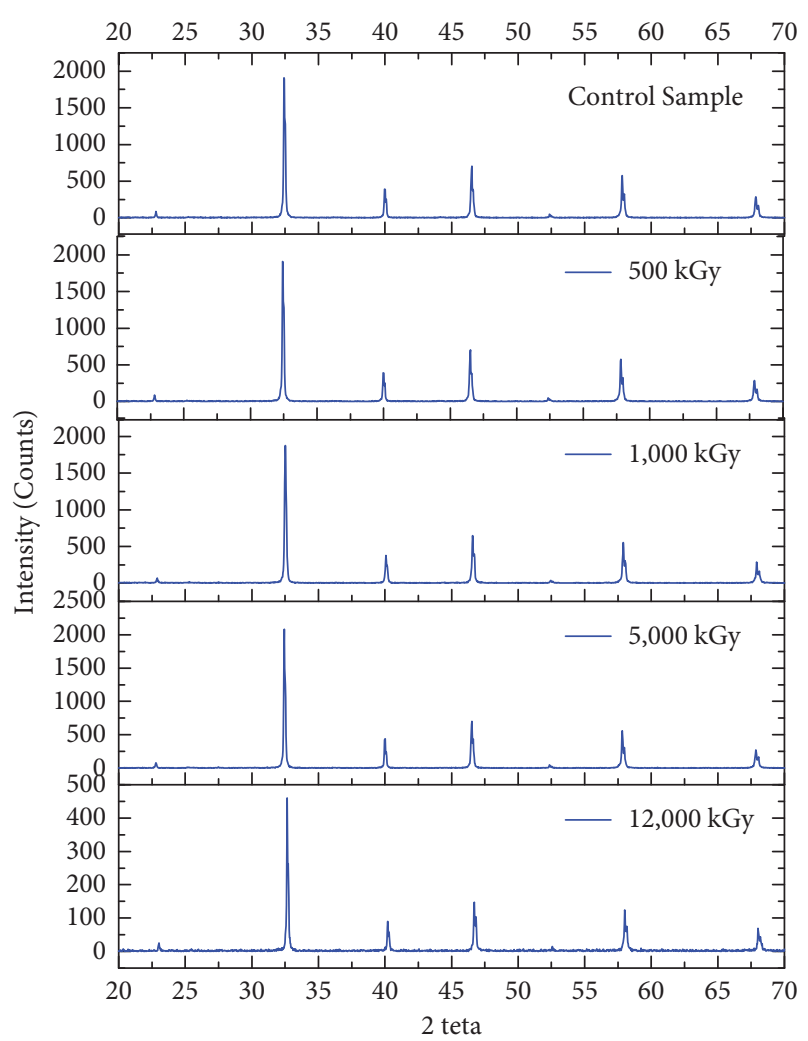

FIGURE 1: XRD patterns of irradiated and nonirradiated tausonite.

irradiation, the above could cause deformations within the unit cell due to a change in the distance between oxygen, iron, magnesium, or any metal ions [30]. The second reason is because the intensity lines can change in the diffractograms and can be explained by the supply of additional energy to the crystal influenced by gamma radiation, which can increase the vibrations of the crystal lattice [30]. Any of the above reasons can change the number of diffraction particles in the plane and thus change the intensity line in the diffractograms.

The micrographs of the irradiated samples are presented in Figure 2. The figure shows that the material has a morphology with aggregates of various polyhedral shapes tending to spherical shapes ranging in size from $500 \mathrm{~nm}$ to $1 \mu \mathrm{m}$. These results suggest that gamma irradiation causes agglomeration and reduction in particle size. Furthermore, the results of the BET analysis indicate that the samples at $12000 \mathrm{kGy}$ have a mean pore diameter of $23.9 \mathrm{~nm}$ and a total pore volume of $0.087 \mathrm{~cm}^{3} / \mathrm{g}$. Nonirradiated tausonite has a mean pore diameter of $13.6 \mathrm{~nm}$ and a total pore volume of $0.04 \mathrm{~cm}^{3} / \mathrm{g}$. The specific area does not show significant changes between the irradiated and nonirradiated samples. These results suggest that gamma irradiation causes a slight increase in the porosity of the material.

Figure 3 shows the thermogravimetric curve of the tausonite sample. An endothermic peak is observed at $1009.73 \mathrm{~K}\left(736.58^{\circ} \mathrm{C}\right)$ that is related to the desorption of the water molecules added in the structure of the material; the above is verified with the gradual loss of the original mass of the sample $(1.41 \%)$ [31, 32]. An exothermic peak occurs at
$1168.12 \mathrm{~K}\left(894.97^{\circ} \mathrm{C}\right)$, with a rapid loss of mass equivalent to $1.88 \%$. This weight loss has been observed by other authors and is usually associated with decomposition of $\mathrm{SrCO}_{3}$ into $\mathrm{SrO}$ and $\mathrm{CO}_{2}$ with the consequent release of $\mathrm{CO}_{2}[33,34]$. This could be related to impurities from the tausonite synthesis process. By relating the XRD and TGA results, it can be established that tausonite is thermostable at the tested temperatures and can easily withstand the maximum thermal energy limit $\left(2 \mathrm{~kW} / \mathrm{m}^{3}\right)$ recommended in the Waste Acceptance Criteria for disposal [18].

Figure 4 shows the IR spectra of the uncalcined tausonite samples and those calcined at $1023.15 \mathrm{~K}\left(750^{\circ} \mathrm{C}\right)$ and $1173.15 \mathrm{~K}\left(900^{\circ} \mathrm{C}\right)$. The figure shows the IR spectrum of uncalcined tausonite, where it can be observed that the absorption peaks at $3448 \mathrm{~cm}^{-1}$ and $1633 \mathrm{~cm}^{-1}$ are produced by the vibration of hydroxyl [31]. The hydroxyl group was probably derived from the adsorption water on the surface of the sample. At $2364 \mathrm{~cm}^{-1}$, the presence of $\mathrm{CO}_{2}$ (from the environment) absorbed by the sample was observed. The absorption bands at $1383 \mathrm{~cm}^{-1}$ and $1458 \mathrm{~cm}^{-1}$ are attributed to two tension modes of the unidentate $\mathrm{CO}_{3}^{-}$of $\mathrm{SrCO}_{3}$ [35]. The broad absorption bands around 409 and $596 \mathrm{~cm}^{-1}$ correspond to bending and stretching vibrations of the $\mathrm{TiO}_{6}$ octahedron, respectively. The absorption peak at $596 \mathrm{~cm}^{-1}$ belonged to the stretching vibration characteristic of the $\mathrm{Sr}$ Ti-O bond $[31,36]$. The overlap of the bands in the range of $471-523 \mathrm{~cm}^{-1}$ of the infrared assignments shows the vibration of metal cations, such as $\mathrm{Sr}^{2+}$ [37]. At the tested temperatures, the absorption peaks at $3448 \mathrm{~cm}^{-1}$ and $1633 \mathrm{~cm}^{-1}$ caused by the hydroxyl vibration decrease as the temperature increases. Likewise, it is observed that the band at $1458 \mathrm{~cm}^{-1}$ of $\mathrm{CO}_{3}^{-}$remains, which is explained by the presence of $\mathrm{SrCO}_{3}$ (tausonite impurity).

\subsection{Sorption Experiments}

3.2.1. Sorption Kinetics Modelling. Figure 5(a) presents the results of europium sorption as function of time. These results were used to evaluate sorption kinetics and determine the retention capacity of tausonite. In Figures 5(b) and 5(c), the results of the linearization tests are presented to determine the order of the sorption kinetics using the Elovich (equation (6)) and pseudo-first-order equations (equation (7)):

$$
\begin{aligned}
q_{t} & =\alpha+2.303 \beta \log (t), \\
\ln \left(q_{e}-q_{t}\right) & =\ln \left(q_{e}\right)-k_{1} t .
\end{aligned}
$$

The fitting equations of expressions 6 and 7 were obtained by plotting $q_{t}$ versus $\log (t)$ and $\ln \left(q_{e}-q_{t}\right)$ versus $t$, respectively. In both cases, the slopes and ordinates of the fitting equations allowed calculating the kinetic parameters of each of the models. As shown in Figure 5(b), the Elovich model exhibits a Pearson correlation and a statistical correlation coefficient $\left(R^{2}\right)$ of 0.98 and 0.95 , respectively. These correlations and confidence bands (95\%) show that the model can mathematically explain the experimental data. The kinetic parameters $\alpha$ and $\beta$ of the model were calculated 


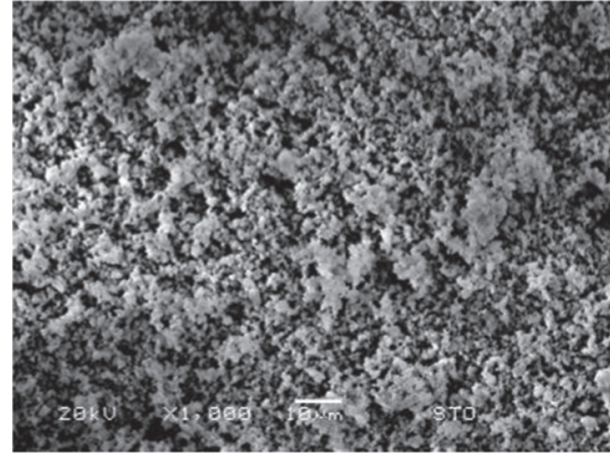

(a)

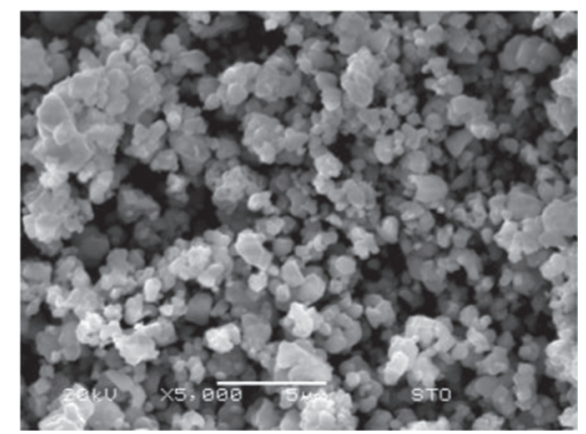

(b)

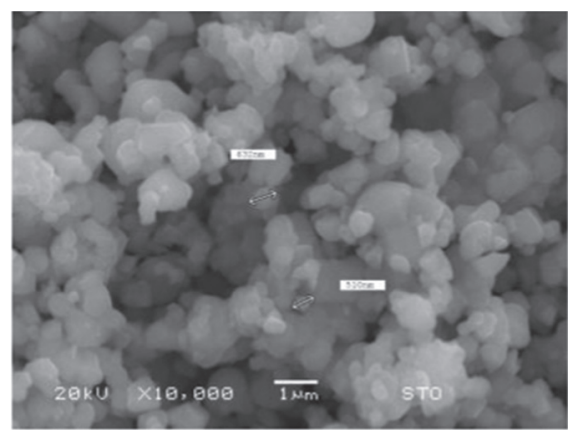

(c)

Figure 2: Micrographs of tausonite irradiated at $12000 \mathrm{kGy}$. (a) 1000x, (b) 5000x, and (c) 10000x.

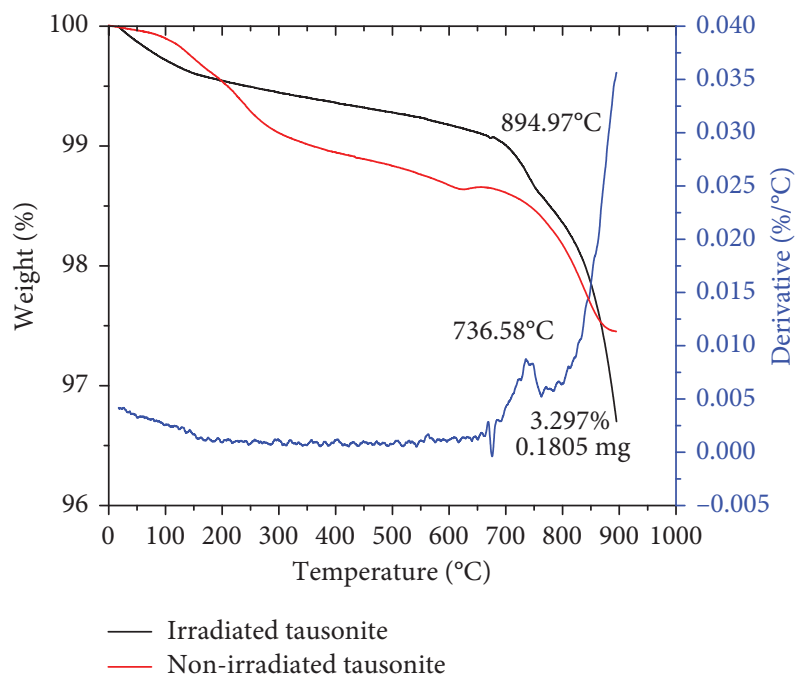

FIGURE 3: TGA/DSC analysis of irradiated and nonirradiated tausonite.

using the adjustment equation, obtaining $\alpha<0$ and $\beta=0.138 \mathrm{mg} / \mathrm{g}$, and the product of $\alpha \beta=0$. Despite the fact that the adjustment presents high correlation values, it should be considered that the model restricts that the product of $\alpha \beta$ must be much greater than 1 [23]. In this context, it can be established that Elovich's expression does not explain phenomenologically the europium retention process in tausonite.

Figure 5(c) shows the fit of the experimental data using the pseudo-first-order kinetic model (Lagergren equation).

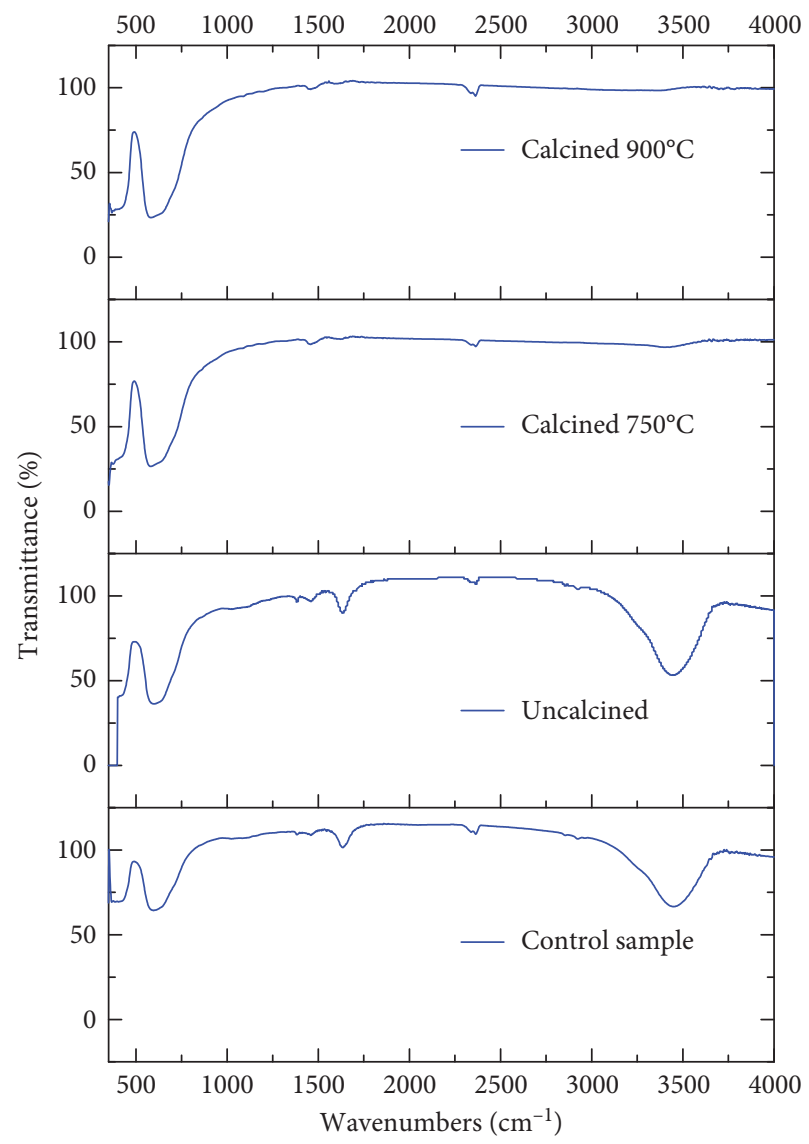

FIGURE 4: IR spectra of calcined and uncalcined tausonite at $1023.15 \mathrm{~K}\left(750^{\circ} \mathrm{C}\right)$ and $1173.15 \mathrm{~K}\left(900^{\circ} \mathrm{C}\right)$. 


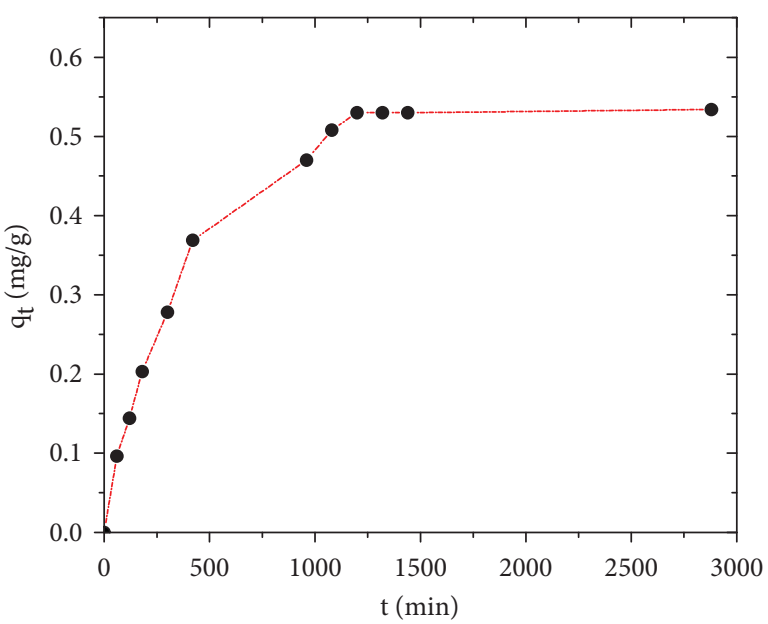

-.-.- Experimental data

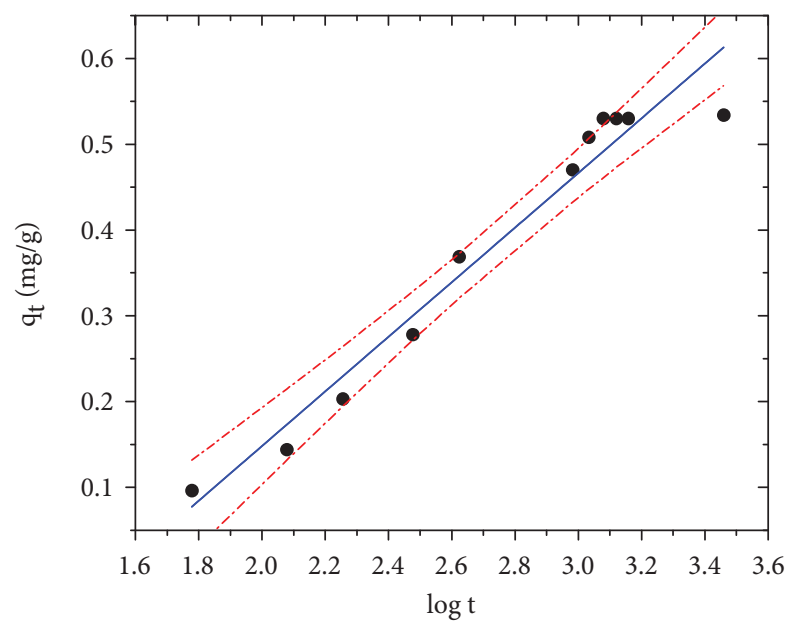

- Experimental data

- Data fitting

-..-.- 95\% Confidence band

(b)

(a)

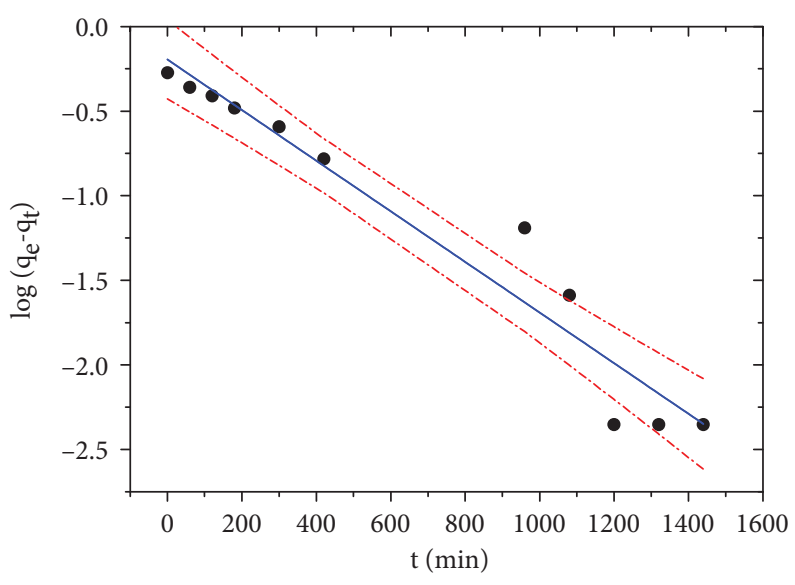

- Experimental data

Data fitting

-.-- 95\% Confidence band

(c)

Figure 5: (a) Sorption of europium as a function of time on tausonite, using a $1 \times 10^{-4} \mathrm{M}$ solution of EuNO $\mathrm{N}_{3}$, in contact with $400 \mathrm{mg}$ of material at a constant $\mathrm{pH}$. (b) Fitting of experimental data using the linearized equation of the Elovich model. (c) Fitting of experimental data of the pseudo-first-order model.

As shown in the figure, the fitting equation shows a high correlation of Pearson and $R^{2}$ (0.98 and 0.94 , respectively) with a $95 \%$ confidence level between the experimental data and the pseudo-first-order model. The slope and ordinate of the fitting equation allowed estimating the values of $k_{1}=0.0034 \mathrm{~min}^{-1}$ and $q_{e}=0.64 \mathrm{mg} / \mathrm{g}$. The relative error $\left(E_{R}\right)$ observed with respect to $q_{e}$ was estimated at $19.85 \%$, which indicates that the model is relatively appropriate to explain the sorption of europium in the tausonite.

On the other hand, Figure 6(a) presents the results of the fitting of the experimental data with respect to the pseudosecond-order kinetic model given by

$$
\frac{t}{q_{t}}=\frac{1}{h}+\frac{t}{q_{e}} .
$$

This figure was made by plotting $t / q_{t}$ versus $t$. The fitting equation obtained allowed estimating the kinetic constants $k_{2}=0.0026 \mathrm{~g} \mathrm{mg} / \mathrm{min}$ and $q_{e}=0.61 \mathrm{mg} / \mathrm{g}$, with a Pearson correlation and $R^{2}$ of 0.99 . The correlation coefficients and confidence bands show that the model satisfactorily explains the experimental data. Likewise, the magnitudes of $k_{2}$ and $q_{e}$ are congruent from a physical point of view, observing an $E_{R}$ of $14.23 \%$ with respect to $q_{e}$.

Comparing the pseudo-first-order and pseudo-secondorder models, it is evident that both kinetic models present 


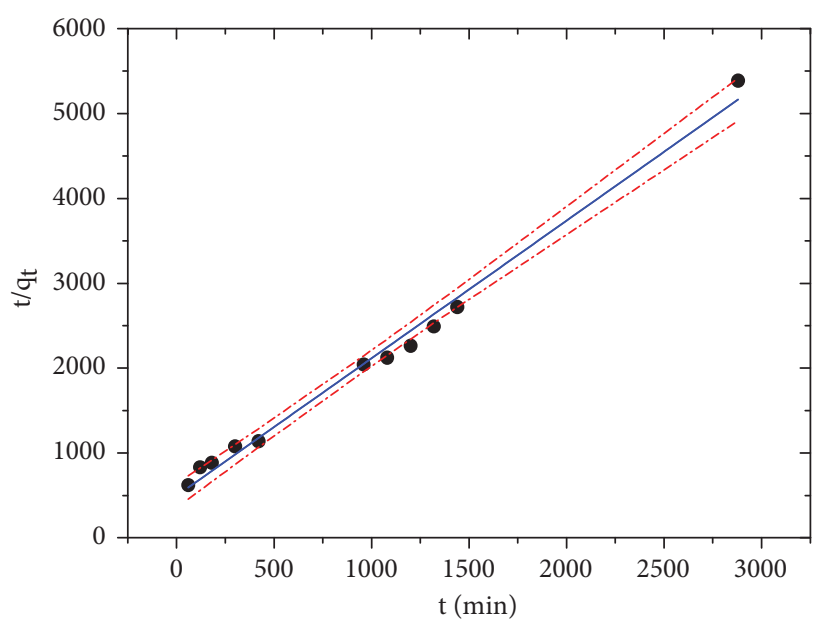

- Experimental data

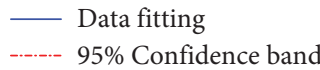

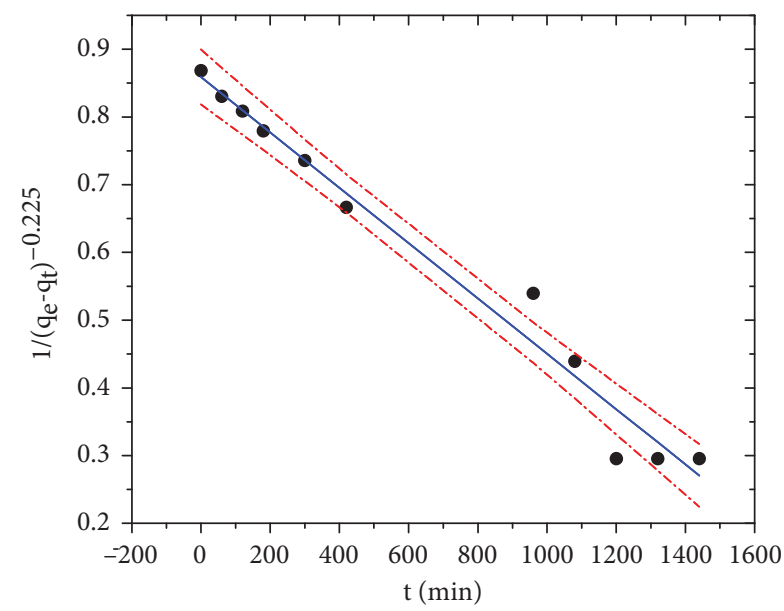

- Experimental data

_ Data fitting

-..-. 95\% Confidence band

(a)

(b)

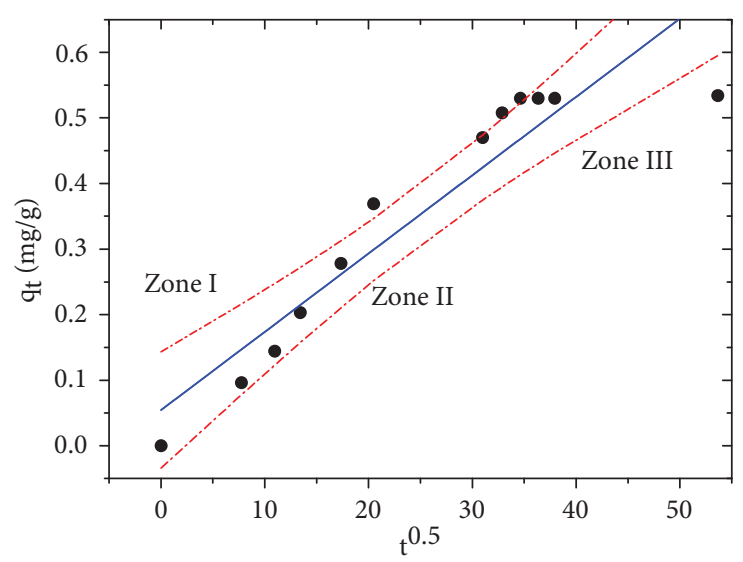

- Experimental data

- Data fitting

-.--.- 95\% Confidence band

(c)

FiguRE 6: (a) Fitting of experimental data using the pseudo-second-order model. (b) Fitting of experimental data using pseudo-order model $\left(k_{n} ; n \neq 1\right)$. (c) Fitting of experimental data using intraparticle model.

high correlation coefficients with a difference between the models of around $5.62 \%$ of $E_{R}$. It is observed that this discrepancy may be due to the number of experimental data points and some experimental fluctuations in dispersion around the general trend. The doubt about the choice between the first and second pseudo-order allows us to think of a process with a probable optimal pseudo-order $\left(k_{n} ; n \neq 1\right)$ to correlate the retention of europium in tausonite:

$$
q_{t}=q_{e}\left\{1-\left[(n-1) k_{n} t+1\right]^{(1 / 1-n)}\right\}
$$

where the intermediate pseudo-order can be determined by nonlinear regression or by linearization with equation (10). As shown in Figure 6(b), the fitting equation allowed us to obtain the kinetic order of the europium retention process, which was estimated at a value of $n=0.775$, $k_{0.775}=0.0019 \mathrm{~min}^{-1}$, and $q_{e}=0.97 \mathrm{mg} / \mathrm{g}$. The results of the statistical analysis exhibited a Pearson correlation and an $R^{2}$ of 0.98 and 0.97, respectively. Although the statistical analysis showed that the model is adequate to explain the retention process, the relative error associated with the sorption capacity in the equilibrium estimated by the model was very high $\left(E_{R}=81.65 \%\right)$. Under these conditions, it is shown that this model does not physically explain the europium retention process in perovskites:

$$
\frac{1}{\left(q_{e}-q_{t}\right)^{n-1}}=\frac{(n-1) k_{n}}{q_{e}^{n-1}} t+\frac{1}{q_{e}^{n-1}} .
$$

Additionally, the role of diffusive phenomena in the europium interaction process with an engineering barrier formed by tausonite was studied. For this, the empirical model of fractional order was used, as expressed in 


$$
q_{t}=k_{0.5} \sqrt{t}+C .
$$

This model allows defining the influence of intraparticle diffusion on the solute retention process [38]. In this context, Figure 6(c) represents $q_{t}$ as a function of $t^{0.5}$. The fitting equation presents an adequate Pearson correlation and $R^{2}$ of 0.94 and 0.87 , respectively. This fitting equation allowed estimating the kinetic parameters of the model: $k_{0.5}=0.0119 \mathrm{mg} / \mathrm{g} \cdot \mathrm{min}^{0.5}$ and $C=0.0545 \mathrm{mg} / \mathrm{g}$, where $C$ is related to the thickness of the surface layer formed on the tausonite [23]. However, to give a possible additional physical significance to the intraparticle diffusion rate constant $\left(k_{0.5}\right)$, equation (11) was rewritten in a new expression (see equation (12)) with a new derived parameter $(\tau)$, which designates the characteristic intradiffusion time and the normalized intraparticle diffusion rate. In this case, $\tau$ was estimated at $7.06 \mathrm{~min}$ :

$$
q_{t}=k_{i d}^{0} q_{e} \sqrt{t}+C
$$

where

$$
\tau=\frac{1}{k_{i d}^{0^{2}}} .
$$

The results of fitting of the experimental data suggest that the europium retention process in tausonite can be explained by interpreting three zones [39], which can be seen in Figure 6(c). Zone I is attributed to the diffusional process of $\mathrm{EuNO}_{3}^{2+}$ on the surface of the material; therefore, this was the fastest sorption period. Zone II suggests a slight intraparticle diffusion, which occurs in a delayed process. Zone III could be considered as the diffusion through the smallest pores of the material, which is followed by the establishment of equilibrium. This behavior could be related to the increase in porosity caused by irradiation of tausonite. This statement is supported by observations made by other authors, who have indicated that when the fit data respond to more than one line of fit, it is indicative that the sorption process is influenced by more than one diffusion phenomenon [13, 40, 41].

The results of fitting of the experimental data with the kinetic models studied clearly show that the sorption of europium in tausonite follows a pseudo-second-order behavior, which implies that the europium is retained in the tausonite by the formation of strong bonds. Different authors have observed that when the experimental data are fitted to a pseudo-second-order model, they indicate the formation of strong bonds and, in some cases, chemisorption between sorbents/sorbates [20, 24]. In this context, the observed retention process is consistent with previous studies in tausonite, which have demonstrated that the material forms bidentate surface complexes associated with the interaction of the surface sites $\mathrm{TiOH}_{2}^{2+}$ and $(\mathrm{TiOH})_{2}$ [14]. Furthermore, the results obtained by fitting the intraparticle model indicate that the sorption mechanism is influenced by more than one diffusion phenomenon, and they contribute to the formation of surface complexes. This diffusive process is physically related to the parameter $\tau$ estimated in the model $(\tau=7.06 \mathrm{~min})$, as has been observed with other materials [39-41].
From a practical point of view, an engineering barrier is required to have physical and chemical properties that provide containment of radionuclides and prevent them from being released and migrating from a waste package [16]. The characteristics of the waste package are defined by the waste acceptance criteria; thus, the waste package represents the first containment barrier for radionuclides and usually consists of a waste container that is filled with a solid matrix (encapsulant) that is sealed with a lid $[17,18]$. The most important safety criteria of the waste package during the operational period and after the closure of the disposal site are the chemical and physical properties of the waste package, the dimensions and weight of the package, permissible levels of radioactivity, radiation dose rate, and allowed heat generation [16-18].

In order to carry out a preliminary evaluation of tausonite as an engineering barrier in a normal scenario of safety assessment, two basic aspects of the waste package should be considered: the permissible specific activity of long-lived alpha-emitting radionuclide $(4000 \mathrm{~Bq} / \mathrm{g})$ and a thermal power of approximately $2 \mathrm{~kW} / \mathrm{m}^{3}$ [16-18]. In this context, in an extreme hypothetical case in which all alphaemitting radionuclides $\left(\mathrm{Ac}^{3+}\right)$ were released from the waste package, an engineered tausonite barrier would have to retain at least $26.59 \mathrm{~g}$ of alpha-emitting radionuclides, equivalent to $4000 \mathrm{~Bq} / \mathrm{g}$ of actinides $\left(\mathrm{Ac}^{3+}\right)$ isotopes and a waste package of approximately $900 \mathrm{~kg}$. In this scenario, if the tausonite has a sorption capacity of $0.54 \mathrm{mg}$ of radionuclides per gram of tausonite, approximately $50 \mathrm{~kg}$ of engineered barrier would be needed as a buffer material, which is an acceptable value from a technical and economic point of view. Considering that a thermal power of $2 \mathrm{~kW} / \mathrm{m}^{3}$ is much lower than the thermal processes tested, it is possible to affirm that the tausonite would not suffer deterioration due to thermal fields and gamma irradiation, as has been demonstrated in the experimental tests.

3.2.2. Modelling Concentration Dependence as a Function of $p H$. Figure 7 shows the concentration dependence as a function of $\mathrm{pH}$. The two plateaus at the beginning and end of the $\mathrm{pH}$ range suggest that equation (14) has only three adjustable parameters, $q_{t}, \mathrm{pH}_{0}$, and $\pi$ to fit this variation:

$$
q_{t}=\frac{q_{e} \cdot e^{\left(\mathrm{pH}-\mathrm{pH}_{0} / \pi\right)}}{1+e^{\left(\mathrm{pH}-\mathrm{pH}_{0} / \pi\right)}},
$$

where $\mathrm{pH}_{0}=6.2$ and $\pi=2.2$.

Considering that the error of the experimental measurements is less than $5 \%$, Figure 7 shows a reliable concordance between the experimental and estimated values. As can be seen in the figure and in equation (14), $\mathrm{pH}_{0}$ is the value of the jump center where the sorption capacity of tausonite reaches half the limit retention capacity, $q_{t}$. The jump range $(\Delta \mathrm{pH})$ is approximately

$$
\Delta \mathrm{pH}=\mathrm{pH}_{0} \pm \frac{\pi}{2} \text {. }
$$

Furthermore, it is probable that $\mathrm{pH}_{0}$ is in causal correlation with the diagram of Figure 7 . It should be noted that 


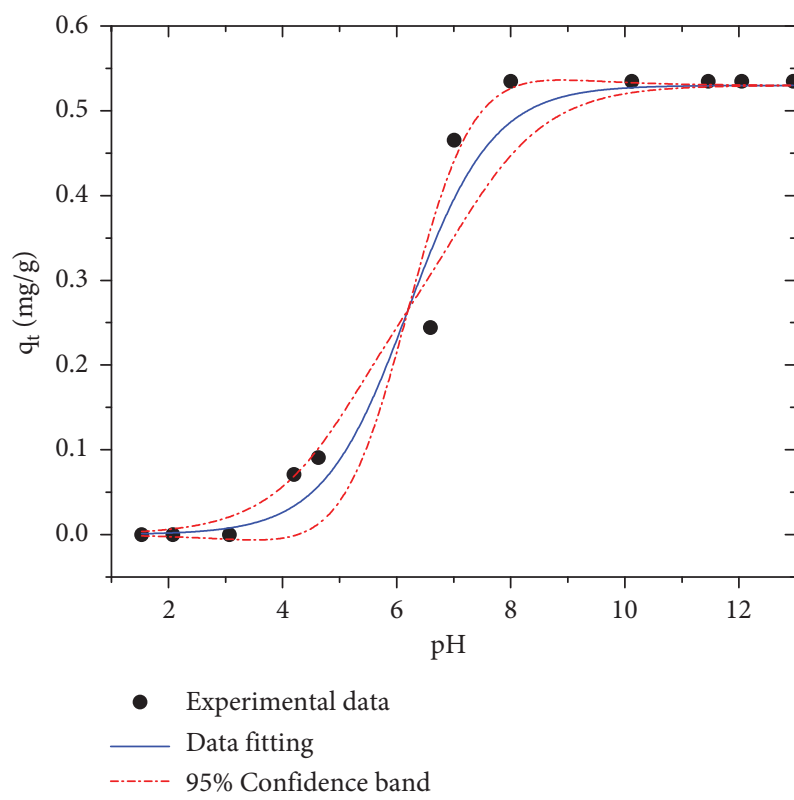

FIGURE 7: Variation of the sorption capacity with the $\mathrm{pH}$ and values estimated by means of the proposed equation.

the speed of the jump is characterized by the amount of $\pi=2.2$ (see equation (16)).

$$
\mathrm{pH}=\mathrm{pH}_{0}+\pi \ln \frac{q_{t}}{q_{e}-q_{t}},
$$

where $\pi$ is also physically equivalent to the amount of $\mathrm{pH}$. In this context, it is possible that its value (2.2) is related to any optimal property value, or the beginning of a certain phenomenon, equilibrium phase, or the formation or disappearance of a certain species. Previous studies of the variation of europium concentration versus $\mathrm{pH}$ in tausonite showed that this curve can be deconvolved and explained by the formation of a bidentate surface complex $\left((\mathrm{TiOH})_{2} \mathrm{EuNO}_{3}^{2+} ; \log K=9.08 \pm 0.02\right)$, the chemical precipitation, and surface europium hydroxyl and carbonate species [15]. The $\mathrm{pH}$ of 6.2 associated with the physical parameter $\pi$ coincides with the saturation of the surface sites of the species $\equiv \mathrm{TiOH}_{2}^{2+}$ with $\mathrm{EuNO}_{3}^{2+}$ that form the bidentate complex, at the beginning of the chemical and surface precipitation of the hydroxylated and carboxylated species of europium and which validates the hypothesis of the physical meaning of the parameter $\pi$ deduced with the proposed model. Due to the mathematical property of the suggested model, it is likely that $2 \pi=4.4$ has the physical significance that explains the equilibrium between the surface complexes that tausonite forms on europium. It is important to note that this equation must be handled with great mathematical caution due to the definition domain $\left(0^{+}<q_{t}<q_{e}\right)$.

Based on the above, it is possible to establish that this model can be used to predict values of sorption capacity for $\mathrm{pH}$ other than the experimental data points. Furthermore, the parameter values can be an excellent criterion when comparing them with the values of other similar studied systems under different conditions.
3.3. Thermodynamic Study. The values of the enthalpy change $\left(\Delta H^{\circ}\right)$, entropy change $\left(\Delta S^{\circ}\right)$, and Gibbs free energy change $\left(\Delta G^{\circ}\right)$ at different temperatures were estimated with equation (3) and data on the europium sorption data. In Figure $8(\mathrm{a})$, the variation of $\Delta G * / T$ is presented as a function of the inverse of the reciprocal temperature $(1 / T)$ for the studied system, obtained with equation (5) (linear regression) and equation (17) (second-grade nonlinear regression). A preliminary inspection of the systems studied through Figure 8(a) shows a discrepancy between the straight line and the uncertainty bars of some of the experimental scattering points. Therefore, it can be established that the nonlinear regression fitting is the best to reduce this discrepancy and obtain more accurate and true values of the two thermodynamic parameters $\Delta H^{\circ}$ and $\Delta S^{\circ}$. So, equation (5) is replaced by a polynomial equation with two or three degrees expressed as follows [28]:

$$
\frac{\Delta G_{T}^{\circ}}{T}=A_{0}+A_{1}\left(\frac{1}{T}\right)+A_{2}\left(\frac{1}{T}\right)^{2}+A_{3}\left(\frac{1}{T}\right)^{3}+\ldots
$$

It can be seen that the mathematical derivation of equation (4) allows determining $\Delta H^{\circ}$ and $\Delta S^{\circ}$ using the following equations [42]:

$$
\begin{aligned}
& \Delta H^{\circ}(T)=\left(\frac{\partial\left(\Delta G_{T}^{\circ} / T\right)}{\partial(1 / T)}\right)_{P}, \\
& \Delta S^{\circ}(T)=-\left(\frac{\partial\left(\Delta G^{\circ}\right)}{\partial(T)}\right)_{P}=\frac{\Delta H^{\circ}-\Delta G_{T}^{\circ}}{T} .
\end{aligned}
$$

In Figure 8(b), the variation of enthalpy as a function of temperature is shown, obtained by nonlinear regression with equation (18). In this figure, the horizontal dashed line represents the constant value determined by linear regression. In Figure 8(c), the variation of entropy as a function of temperature is shown (equation (19)). Similarly, the horizontal dashed line represents the constant value determined by linear regression. From these figures, it can be determined that the values of thermodynamic parameters, $\Delta H^{\circ}$ and $\Delta S^{\circ}$, obtained by nonlinear regression can vary around and on both sides of the constant values obtained by linear regression. For this reason, several interpretations made by experimenters in the literature using only linear regression give a general description and are globally reliable but cannot give precise temperature effects that allow choosing which optimal temperature is preferable.

In this study, $\Delta G^{\circ}, \Delta H^{\circ}$, and $\Delta S^{\circ}$ are negative; additional information indicates that this negativity is accentuated when the temperature increases, which means that the process releases more energy with the temperature. The magnitude of the thermodynamic potential makes it possible to establish that europium retention in tausonite is an exothermic and spontaneous reaction at the tested temperatures, and these observations are consistent with sorption thermodynamics when the surface of the material is not yet saturated [28]. On the other hand, the magnitude of $\Delta H^{\circ}$ indicates that the sorption of europium is due to the formation of surface complexes. Studies using time-resolved 


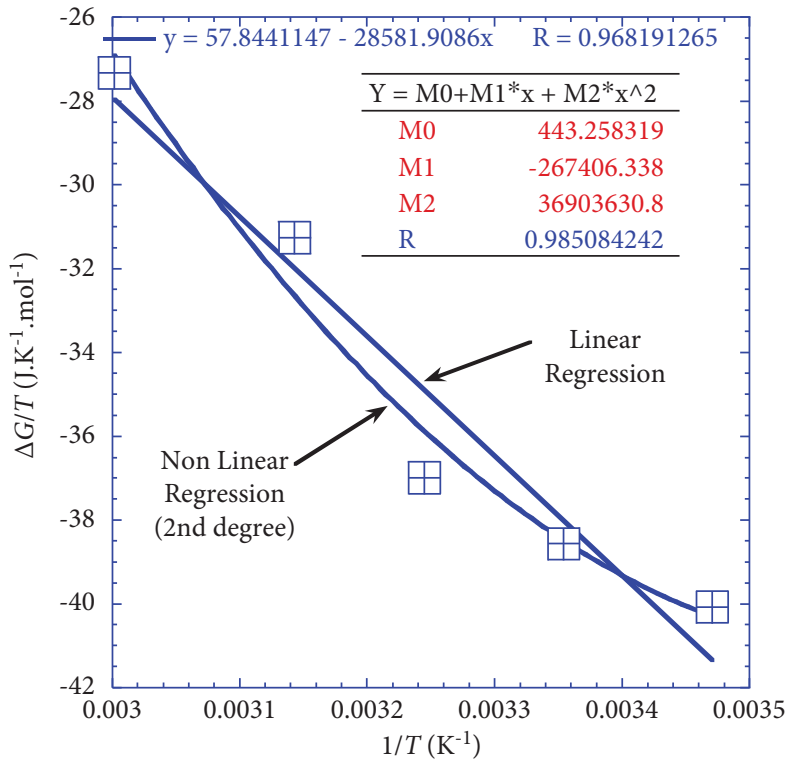

(a)

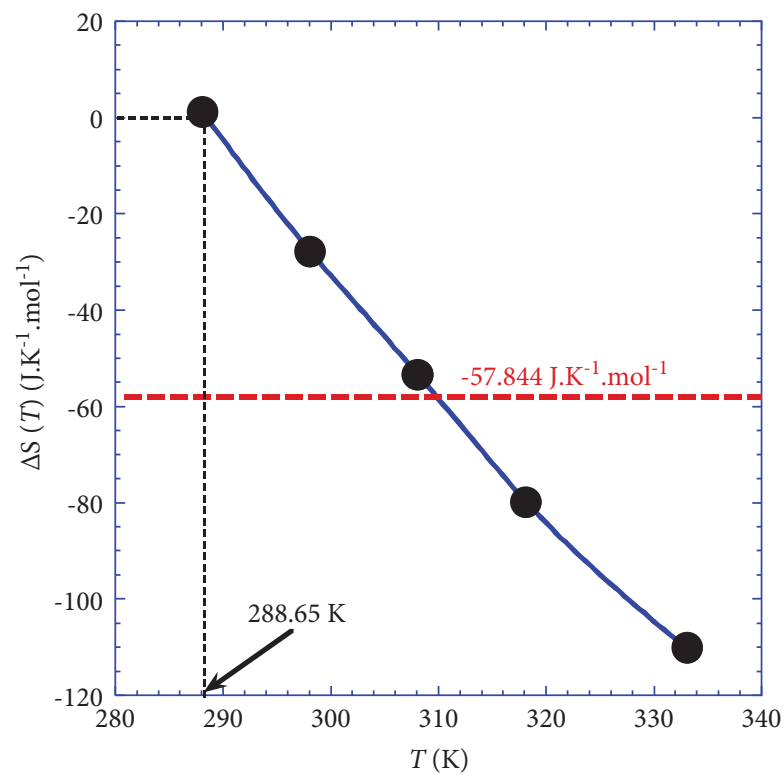

(c)

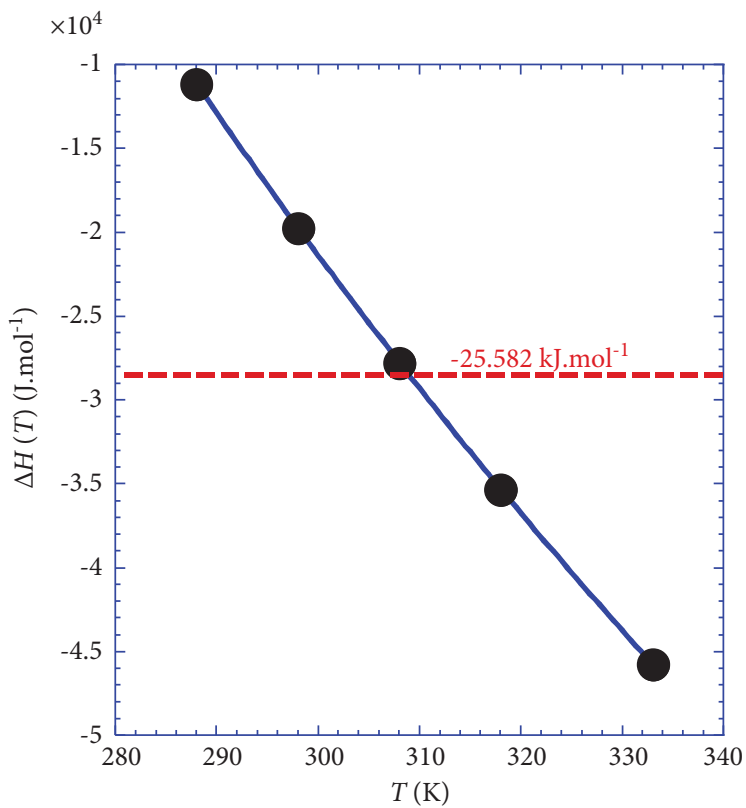

(b)

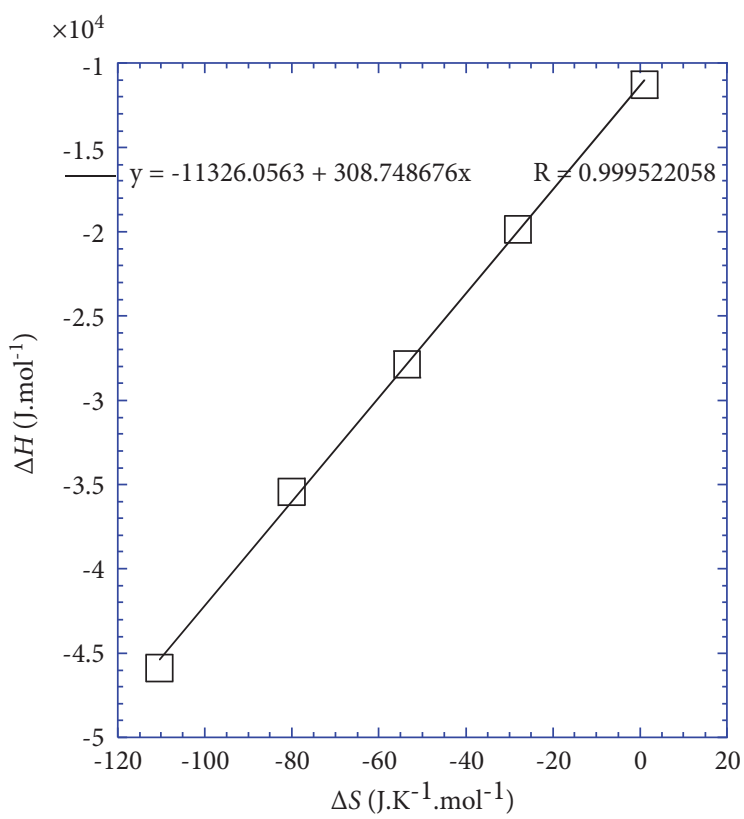

(d)

Figure 8: (a) Variation of $\Delta G / T$ as a function of the inverse of the reciprocal temperature. (b) Variation of $\Delta H^{\circ}$ with temperature obtained by linear regression. (c) Variation of $\Delta H^{\circ}$ with temperature obtained by nonlinear regression. (d) Correlation between the $\Delta H^{\circ}$ and $\Delta S^{\circ}$ for the system.

laser-induced fluorescence spectroscopy and X-ray photoelectron spectroscopy show that the energy transfer between the $\mathrm{Eu}^{3+}$ ions sorbed on the tausonite follows a dipole-dipole interaction and the formation of a bidentate inner-sphere surface complex [43]. Other complexes on the surface of the inner sphere have been observed in the retention of europium in various solids $[19,44]$. In the same context, $\Delta S^{\circ}$ is globally negative and its negativity is accentuated when the temperature increases; this tendency of the $\Delta S^{\circ}$ is explained by the imbalance of the surface forces in the material caused by the transfer of sorbate from the aqueous phase to the surface of the sorbent [28].

However, there is an interesting particularity; the entropy is cancelled at $T=288.65 \mathrm{~K}$ and takes positive sign for lower values than $288.65 \mathrm{~K}$. The positive value found at this temperature may indicate an increase in the disorder in the liquid/solid interface during the interaction of the surface sites with $\mathrm{EuNO}_{3}^{2+}$; another reason could be due to the greater number of ions that leave the surface of the solid when they are exchanged for $\mathrm{EuNO}_{3}^{2+}$, particularly if the 
charge density of $\mathrm{EuNO}_{3}^{2+}$ exceeds the charge of the ions exchanged outside the surface of the tausonite [29]. On the other hand, the fact that $\Delta S^{\circ}=0$ at $T=288.65 \mathrm{~K}$ makes it possible to propose eliminating the temperature as an independent variable and plot in Figure 8(d) $\Delta H^{\circ}$ versus the entropy $\Delta S^{\circ}$. Then, the practically linear enthalpy-entropy dependence shown in Figure 8(d) can be expressed as follows:

$$
\Delta H_{c}^{\circ}=T_{c}\left[\Delta S^{\circ}(T)-\Delta S_{c}^{\circ}\right],
$$

where $T_{c}$ and $\Delta S_{c}^{\circ}$ are the characteristic temperature and the characteristic entropy of the studied system, respectively. By analogy, if we can set that also $T_{c} \Delta S_{c}^{\circ}$ product is equivalent to the characteristic, $\Delta H_{c}^{\circ}$ can be expressed as follows:

$$
\Delta H_{c}^{\circ}==T_{c i} \Delta S_{c}^{\circ} \text {. }
$$

And equation (21) can be rewritten as follows:

$$
\Delta H^{\circ}=T_{c} \Delta S^{\circ}(T)+\Delta H_{c}^{\circ} .
$$

Then, it follows that the investigated system has two main independent specific parameters, $\Delta H_{c}^{\circ}$ and $\Delta S_{c}^{\circ}$, and a dependent parameter $T_{c}$, which can be derived simply by means of equation (21). The estimated values of the specific individual thermodynamic parameters for the studied system were $\Delta H_{c}^{\circ}=-11.326 \mathrm{~kJ} / \mathrm{mol}$ and $\Delta S_{c}^{\circ}=36.684 \mathrm{~J} / \mathrm{kmol}$ with $R^{2}$ of 0.99 . These values correspond to a $T_{c}=35.6^{\circ} \mathrm{C}$ $(308.75 \mathrm{~K})$. However, $\Delta H_{c}^{\circ}$ and $\Delta S_{c}^{\circ}$ can be considered as independent and characteristics specific parameters for a well-determined and investigated system, while in the case of $T_{c}$, care must be taken because it cannot be characteristic of the studied system; it is only an intermediate mathematical variable that obeys equation (23) by simply indicating approximately the temperature of the system during its processing:

$$
\frac{\left(\partial\left(\Delta H^{*}\right) / \partial T\right)_{P}}{\left(\partial\left(\Delta S^{*}\right) / \partial T\right)_{P}}=\frac{C_{P}}{\left(C_{P} / T\right)}=T .
$$

Additionally, it can be observed that $T_{c}$ is very close to the value of the mean temperature $\left(T_{m d}=37.5^{\circ} \mathrm{C}\right)$ of the studied system. This mathematical property is due to the relationship between the slope and the intercept on the ordinate of the tangent line to the curve at a given point for the function $\Delta G * / T=f(1 / T)$ when this point moves along the curve line (Figure 8(a)), that is, when $T$ varies in the working temperature range. When a thermodynamic parameter $\Delta H^{\circ}(T)$ or $\Delta S^{\circ}(T)$ takes the identical value to one of its corresponding specific parameters $\Delta H_{c}^{\circ}$ or $\Delta S_{c}^{\circ}$, the other thermodynamic parameter becomes null, and the thermal character of the process takes on a reciprocal behavior.

Finally, this finding allows carrying out an interesting comparative study in the future to find an interpretation of the values, amount, and physical significance of the true characteristic parameters $\Delta H_{c}^{\circ}$ and $\Delta S_{c}^{\circ}$ for each system studied in relation to its properties and the experimental conditions of the process.

\section{Conclusions}

The results obtained from the study of the effects of gamma irradiation on tausonite allowed establishing that at the irradiation doses tested, the material undergoes some morphological changes, such as darkening, agglomeration, reduction in particle size, and a slight increase in porosity. Evidence indicates that irradiation does not cause appreciable damage to the crystal structure and does not produce phase changes. The results on the effects of temperature indicate that the material is thermostable at the tested temperatures. Thus, with the evidence presented, it can be stated that the perovskite studied would not suffer deterioration due to thermal fields and gamma irradiation, which could be expected in a radioactive waste disposal site.

On the other hand, the thermodynamic and sorption studies showed that the sorption of europium on tausonite occurs through an exothermic and spontaneous reaction at the tested temperatures and that it follows a pseudo-secondorder behavior. This implies that europium is retained in tausonite by the formation of bidentate inner-sphere surface complexes, where $\mathrm{Eu}^{3+}$ ions bind to sites on the tausonite surface by dipole-dipole interaction, as shown by the thermodynamics of the parameters and the different sorption models tested. The evidence obtained suggests that diffusion of europium at the liquid/solid interface contributes to the initial process of interaction between europium and sites on the surface of the material. This phenomenon could be related to the increase in porosity caused by the irradiation of the material. The modelling of the sorption with respect to the proposed $\mathrm{pH}$ allowed determining the physical parameter $\pi$. The evidence obtained suggests that $\pi$ is a physical parameter that relates $\mathrm{pH}$ to an optimal property value, for example, the equilibrium phase, the formation, or disappearance of chemical species, among others. In this study, due to the mathematical property of the proposed model, it is likely that $2 \pi=4.4$ has the physical meaning that explains the equilibrium between the surface complexes that tausonite forms with europium. Therefore, it can be established that this model can be used for prediction of sorption capacity values for $\mathrm{pH}$ other than the experimental data points. In addition, the values of $\pi$ parameters can be an excellent criterion, when compared with the values of other similar systems studied under different conditions.

Likewise, the evidence suggests that $50 \mathrm{~kg}$ of tausonite would have the capacity to retain at least $26.59 \mathrm{~g}$ of alphaemitting radionuclides $\left(\mathrm{Ac}^{3+}\right)$, equivalent to a waste package $(900 \mathrm{~kg}$ ) with a maximum activity of $4000 \mathrm{~Bq} / \mathrm{g}$. This is quite an acceptable value from a technical and economic point of view.

Finally, the evidence obtained from the evaluation of tausonite, such as its resistance to gamma irradiation and temperature, sorption capacity, and thermodynamic behavior, suggests that this perovskite could be a potential candidate for its use in an engineering barrier in the disposal of radioactive waste. However, additional studies are required on the effects of neutrons on the structure and morphology of tausonite. 


\section{Data Availability}

The datasets used and/or analysed during the current study are available from the corresponding author on reasonable request.

\section{Disclosure}

This work is part of the DR-001 project of the Radioactive Waste Department, National Institute of Nuclear Research (ININ). This work was supported by Benemerita Autonomous University of Puebla. The irradiation of the material was performed by the staff of the ININ gamma irradiator. Dose calculations were estimated by Ing. Hector Carrasco Abrego.

\section{Conflicts of Interest}

The authors declare that they have no conflicts of interest.

\section{Authors' Contributions}

Ortiz-Oliveros H.B. was responsible for conceptualization, investigation, supervision, data curation, methodology, formal analysis, and chemical analysis, prepared the original draft, and reviewed and edited the manuscript. FloresEspinosa R.M. reviewed and edited the manuscript and performed data validation and chemical analysis. Noureddine Ouerfelli was responsible for thermodynamic modelling and mathematical analysis. Avila-Perez P. and Cruz-Gonzalez D. performed data validation and reviewed and edited the manuscript.

\section{References}

[1] S. Patial, V. Hasija, P. Raizada, P. Singh, A. A. P. Khan Singh, and A. M. Asiri, "Tunable photocatalytic activity of $\mathrm{SrTiO}_{3}$ for water splitting: strategies and future scenario," Journal of Environmental Chemical Engineering, vol. 8, no. 3, Article ID 103791, 2020.

[2] F. Toledo, I. Lizana, A. Buljan, X. Zarate, G. Pecchi, and E. J. Delgado, "The adsorption of furfural on $\mathrm{SrTiO}_{3}$ and SrCoxTil- $\mathrm{xO}_{3}$ perovskites: a DFT study within the molecular cluster approach," Journal of Molecular Structure, vol. 1226, Article ID 129333, 2021.

[3] Q. Li, Z. Chen, I. Tranca, S. Gaastra-Nedea, D. Smeulders, and S. Tao, "Compositional effect on water adsorption on metal halide perovskites," Applied Surface Science, vol. 538, Article ID 148058, 2021.

[4] N. T. Mahmoud, A. A. Mousa, and J. M. Khalifeh, "First principles investigation of thermoelectric and mechanical properties of $\mathrm{VScO}_{3}$ semiconductor perovskite for sustainable and renewable energy," Results in Physics, vol. 18, Article ID 103331, 2020.

[5] R. Ishikawa, S. Yamazaki, S. Watanabe, and N. Tsuboi, "Layer dependency of graphene layers in perovskite/graphene solar cells," Carbon, vol. 172, pp. 597-601, 2021.

[6] F. He, M. Lv, M. Lu et al., "Direct current field induced asymmetrical DC-resistivity degradation in $\mathrm{SrTiO}_{3}$-based grain boundary layer ceramic," Ceramics International, vol. 45, no. 10, pp. 13546-13550, 2019.

[7] G. Takalkar, R. R. Bhosale, F. AlMomani et al., "Thermochemical splitting of $\mathrm{CO}_{2}$ using solution combustion synthesized lanthanum-strontium-manganese perovskites," Fuel, vol. 285, Article ID 119154, 2021.

[8] J. Buchwald and M. Hennes, "Adsorption and diffusion of $\mathrm{Au}$, $\mathrm{Pt}$, and $\mathrm{Co}$ adatoms on $\mathrm{SrTiO}_{3}(001)$ surfaces: a density functional theory study," Surface Science, vol. 701, pp. 1-5, 2020.

[9] Z. Chen, B. Hua, X. Zhang et al., "Organic photochemistryassisted nanoparticle segregation on perovskites," Cell Reports Physical Science, vol. 1, no. 11, Article ID 100243, 2020.

[10] J. Hwang, R. R. Rao, L. Giordano, Y. Katayama, Y. Yu, and Y. Shao-Horn, "Perovskites in catalysis and electrocatalysis," Science, vol. 358, no. 6364, pp. 751-756, 2017.

[11] P. Mohammadi, F. Ghorbani-Shahna, A. Bahrami, A. A. Rafati, and M. Farhadian, "Plasma-photocatalytic degradation of gaseous toluene using $\mathrm{SrTiO}_{3} / \mathrm{rGO}$ as an efficient heterojunction for by-products abatement and synergistic effects," Journal of Photochemistry and Photobiology A: Chemistry, vol. 394, 2020.

[12] D. García, J. Lützenkirchen, V. Petrov et al., "Sorption of Eu (III) on quartz at high salt concentrations," Colloids and Surfaces A: Physicochemical and Engineering Aspects, vol. 578, Article ID 123610, 2019.

[13] H. B. Ortiz-Oliveros, R. M. Flores-Espinosa, E. OrdoñezRegil, and S. M. Fernández-Valverde, "Titanium pyrophosphate for removal of trivalent heavy metals and actinides simulated by retention of europium," Science World Journal, vol. 2017, Article ID 2675897, 12 pages, 2017.

[14] H. B. Ortiz-Oliveros, E. Ordoñez-Regil, and S. M. FernándezValverde, "Sorption of uranium (VI) onto strontium titanate in $\mathrm{KNO}_{3}$ medium," Journal of Radioanalytical and Nuclear Chemistry, vol. 279, no. 2, pp. 601-610, 2009.

[15] E. Ordoñez-Regil, H. B. Ortíz-Oliveros, S. M. FernándezValverde, and F. Granados-Correa, "Eu (III) sorption from an aqueous solution onto $\mathrm{SrTiO}_{3}$ and surface complex behavior," Chemical Engineering Journal, vol. 254, pp. 349-356, 2014.

[16] IAEA, Disposal of Radioactive Waste, IAEA, Vienna, Austria, 2011.

[17] IAEA, Scientific and Technical Basis for the Near Surface Disposal of Low and Intermediate Level Waste, IAEA, Vienna, Austria, 2002.

[18] IAEA, The Safety Case and Safety Assessment for the Disposal of Radioactive Waste, IAEA, Vienna, Austria, 2012.

[19] H. B. Ortíz-Oliveros, R. M. Flores-Espinosa, E. OrdoñezRegil, and S. M. Fernández-Valverde, "Synthesis of $\alpha$-Ti( $\left(\mathrm{HPO}_{4}\right)_{2} \mathrm{H}_{2} \mathrm{O}$ and sorption of Eu (III)," Chemical Engineering Journal, vol. 236, pp. 398-405, 2014.

[20] F. Alakhras, N. Ouerfelli, G. Al-Mazaideh, T. Ababneh, E. AlAbbad, and F. Abouzeid, "Optimal pseudo-average order kinetic model for correlating the removal of nickel ions by adsorption on nanobentonite," Arabian Journal for Science and Engineering, vol. 44, no. 1, pp. 159-168, 2019.

[21] S. Álvarez-Torrellas, M. Muñoz, J. A. Zazo, J. A. Casas, and J. García, "Synthesis of high surface area carbon adsorbents prepared from pine sawdust- Onopordum acanthium L. for nonsteroidal anti-inflammatory drugs adsorption," Journal of Environmental Management, vol. 183, pp. 294-305, 2016.

[22] A. Aurich, J. Hofmann, R. Oltrogge et al., "Improved isolation of microbiologically produced $(2 \mathrm{R}, 3 \mathrm{~S})$-isocitric acid by adsorption on activated carbon and recovery with methanol," Organic Process Research \& Development, vol. 21, no. 6, pp. 866-870, 2017.

[23] Y. Ho, "Review of second-order models for adsorption systems," Journal of Hazardous Materials, vol. 136, no. 3, pp. 681-689, 2006. 
[24] Y.-S. Ho, "Second-order kinetic model for the sorption of cadmium onto tree fern: a comparison of linear and nonlinear methods," Water Research, vol. 40, no. 1, pp. 119-125, 2006.

[25] M. Hubbe, S. Azizian, and S. Douven, "Implications of apparent pseudo-second-order adsorption kinetics onto cellulosic materials: a review," BioResources, vol. 14, no. 3, pp. 7582-7626, 2019.

[26] H. Moussout, H. Ahlafi, M. Aazza, and H. Maghat, "Critical of linear and nonlinear equations of pseudo-first order and pseudo-second order kinetic models," Karbala International Journal of Modern Science, vol. 4, no. 2, pp. 244-254, 2018.

[27] W. Plazinski, J. Dziuba, and W. Rudzinski, "Modeling of sorption kinetics: the pseudo-second order equation and the sorbate intraparticle diffusivity," Adsorption, vol. 19, no. 5, pp. 1055-1064, 2013.

[28] A. L. Myers, "Thermodynamics of adsorption," in Chemical Thermodynamics for Industry, T. Letcher, Ed., The Royal Society of Chemistry, London, UK, pp. 243-253, 2004.

[29] F. Granados-Correa and S. Bulbulian, "Co (II) adsorption in aqueous media by a synthetic Fe-Mn binary oxide adsorbent," Water, Air, \& Soil Pollution, vol. 223, no. 7, pp. 4089-4100, 2012.

[30] M. Kądziołka-Gaweł, M. Dulski, L. Kalinowski, and M. Wojtyniak, "The effect of gamma irradiation on the structural properties of olivine," Journal of Radioanalytical and Nuclear Chemistry, vol. 317, pp. 261-268, 2018.

[31] T. Xie, Y. Wang, C. Liu, and L. Xu, "New insights into sensitization mechanism of the doped Ce (IV) into strontium titanate," Materials, vol. 11, pp. 1-17, 2018.

[32] E. Rocha-Rangel, J. Lopez Hernandez, J. A. Rodriguez-Garcia et al., "Dielectric properties of strontium titanate synthesized by means of solid state reactions activated mechanically," Journal of Ceramic Processing Research, vol. 18, pp. 590-593, 2017.

[33] T. Xian, H. Yang, L. Di, J. Ma, H. Zhang, and J. Dai, "Photocatalytic reduction synthesis of $\mathrm{SrTiO}_{3}$-graphene nanocomposites and their enhanced photocatalytic activity," Nanoscale Research Letters, vol. 9, pp. 327-329, 2014.

[34] E. Rosa Silva, M. Curi, J. G. Furtado, H. C. Ferraz, and A. R. Secchi, "The effect of calcination atmosphere on structural properties of $\mathrm{Y}$-doped $\mathrm{SrTiO}_{3}$ perovskite anode for SOFC prepared by solid-state reaction," Ceramics International, vol. 45, no. 8, pp. 9761-9770, 2019.

[35] M. d. C. B. López, G. Fourlaris, B. Rand, and F. L. Riley, "Characterization of barium titanate powders: barium carbonate identification," Journal of the American Ceramic Society, vol. 82, no. 7, pp. 1777-1786, 1999.

[36] T. K. Song, J. S. Ahn, H. S. Choi, T. W. Noh, and S. I. Kwun, "Infrared properties of epitaxial $\mathrm{SrTiO}_{3}$ thin films on $\mathrm{MgO}$ (001) substrates," Journal of the Korean Physical Society, vol. 30, pp. 623-627, 1997.

[37] A. K. Yadav, C. R. Gautam, A. Gautam, and V. K. Mishra, "Structural and crystallization behavior of $(\mathrm{Ba}, \mathrm{Sr}) \mathrm{TiO}_{3}$ borosilicate glasses," Phase Transitions, vol. 86, no. 10, pp. 1000-1016, 2013.

[38] W. Weber, "Kinetics of adsorption on carbon from solution," Journal of the Sanitary Engineering Division, vol. 89, no. 2, 1963.

[39] A. A. Al-Arfaj, F. Alakhras, E. Al-Abbad, N. O. Alzamel, N. A. Al-Omair, and N. Ouerfelli, "Removal of orange $2 \mathrm{G}$ dye from aqueous solutions using $\mathrm{TiO}_{2}$-based nanoparticles: isotherm and kinetic studies," Asian Journal of Chemistry, vol. 30, no. 7, pp. 1645-1649, 2018.
[40] P. N. Diagboya, B. I. Olu-Owolabi, and K. O. Adebowale, "Microscale scavenging of pentachlorophenol in water using amine and tripolyphosphate-grafted SBA-15 silica: batch and modeling studies," Journal of Environmental Management, vol. 146, pp. 42-49, 2014.

[41] V. Fierro, V. Torné-Fernández, D. Montané, and A. Celzard, "Adsorption of phenol onto activated carbons having different textural and surface properties," Microporous and Mesoporous Materials, vol. 111, no. 1-3, pp. 276-284, 2008.

[42] A. Mianowski and W. Urbańczyk, "Enthalpy-entropy compensation for isosteric state adsorption at near ambient temperatures," Adsorption, vol. 23, no. 6, pp. 831-846, 2017.

[43] G. García-Rosales, F. Mercier-Bion, R. Drot, G. Lagarde, J. Roques, and E. Simoni, "Energy transfer from $\mathrm{Tb}^{3+}$ to $\mathrm{Eu}^{3+}$ ions sorbed on $\mathrm{SrTiO}_{3}$ surface," Journal of Luminescence, vol. 132, no. 5, pp. 1299-1306, 2012.

[44] M. Zheng, H. Ji, J. Duan, C. Dang, X. Chen, and W. Liu, "Efficient adsorption of europium (III) and uranium (VI) by titanate nanorings: insights into radioactive metal species," Environmental Science and Ecotechnology, vol. 2, Article ID 100031, 2020. 